\title{
Facilitating Faculty-Driven International Initiatives
}

\author{
James Guikema
}

Associate Vice President for Research

Kansas State University

major, research extensive university must recognize the global scope of
effective scholarship and strive to instill a global perspective in the
classroom, in research and scholarly activities, and in the graduate educational arena. In the shadow of 9/11, the National Science Board published Toward a More Effective Role for the US Government in International Science and Engineering, which made this point very effectively. They stated:

"In a contentious world, bilateral and multilateral cooperation in science and engineering help create a universal language and culture, based on commonly accepted values of objectivity, open-mindedness, tolerance sharing, integrity, and free inquiry."

This concept of free and open inquiry, made richer by exchanges between diverse cultural perspectives and the knowledge that national borders are artificial constraints on scholarship, is core to the higher educational mission of a vibrant university. As Anton Chekhov once stated, "There is no national science, just as there is no national multiplication table."

The goal, therefore, is for the university to achieve a curriculum and an overarching research mission that remains sensitive to a global perspective and seeks to optimize international linkages. Putting such a goal in practice does much in establishing an international reputation for the institution. Similarly, achieving such a goal requires the active participation of the faculty of the institution, with the benefit of enhancing the international reputations of the faculty participants. Faculty members craft the curricula of an institution, and are the hands-on creators of its scholarship. They are busy individuals and abstract benefits such as an enhanced international reputation are not sufficient motivators to drive international collaborations. The distance between Manhattan, KS, and Lincoln, NE, is a barrier to collaborations, and the distance to Munich is much, much greater.

Universities must be proactive to reach the goal of globalization, and the research office can help lead the charge. Kansas State University's Office of Research and Sponsored Programs (OSRP) has identified four challenges that the research administration can address to make globalization and international collaborations a reality.

\section{Challenge \#1: Getting Faculty Members} to Think Globally

As indicated above, the faculty is the key in international collaboration, and distance is an activation energy threshold that needs to be overcome for such collaborations to flourish. 
Certainly, communication technology and the development of collaboration software environments have taken us a long way in mitigating distance as a factor, yet the synergistic value of faceto-face interactions, even if intermittently, can not be overstated.

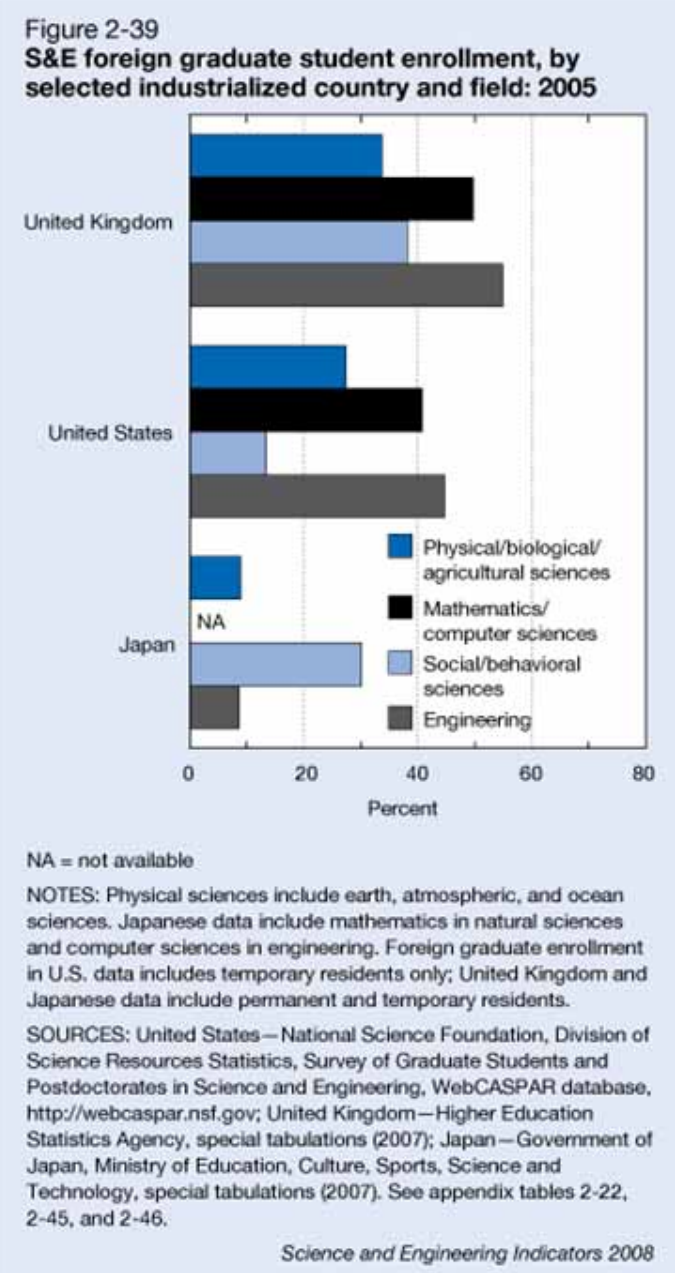

One strategy taken by ORSP is to present the funding opportunities to the KSU faculty in both a timely and a frequent manner. We publish a weekly Funding Bulletin that highlights extramural opportunities from federal, state, and private sources. These opportunities span the range of scholarship at KSU, and are not limited to the STEM disciplines. In addition, we have a section clearly devoted to international and multicultural opportunities.

OSRP has obtained access to several funding databases, including Community of Science. A database specialist is available to assist every faculty member, and especially those in the first several years of their appointments, in obtaining information on funding sources beyond those like NSF and NIH that are well known.

For some faculty members, however, these opportunities do not exist and the strategy of ORSP is to create them. Using internal funding, OSRP maintains two grant programs. The first, a Faculty Development Award program, provides funds for international travel - most often linked to presentations at international conferences. The second, University Small Research Grants program, provides limited funds faculty members in those disciplines where other internal KSU opportunities do not exist and where the opportunities for extramural funding are extremely rare. During the past six years, these two programs have provided over 380 opportunities for international travel and/or research for KSU faculty members.

\section{Challenge \#2: Build on your Strengths}

During the past 5 years, KSU has implemented a process to prioritize and to fund interdisciplinary research as a way to promote collaborative research in a strategic manner. This process, called "Targeted Excellence", integrates research teams in areas that 
our faculty members are already individually successful, with an eye toward large opportunities such as federal center grants like the NSF National Environment Observatory Network program. Often, the collaborative teams that are successful have an international linkage in place.

Two programs that were jumpstarted by the TE process merit special mention. The first, Ecological Genomics, is a new interdisciplinary program that is fast becoming a recognized discipline within its own right. The interrelationship between the genome of a species, both at the individual and at the community levels, and its response to the environment is especially relevant during times of environmental change. This team has built a strong collaboration with colleagues in The Netherlands, and is working to implement faculty and graduate student exchange programs.

Second, the African Area Studies program was enhanced by TE funding. This program is multifaceted. It provides research funding on issues of African politics and economics. It enhances the undergraduate curriculum by providing resources for teaching of African languages. It encourages linkages that have developed in the sciences as well, and has fostered existing linkages with Senegal, Botswana, and South Africa.

We have learned to build on our strengths apart from the TE process as well. OSRP supports extramurallyfunded programs that have international recognition that predates the TE process. One example is the focus on the grasslands of the tallgrass prairie, a program supported by an NSF Long-Term Ecological Research (LTER) grant for the past three decades. An extension of this has been funded by the International LTER to compare the grasslands of KSU's Konza Prairie Biological Station with

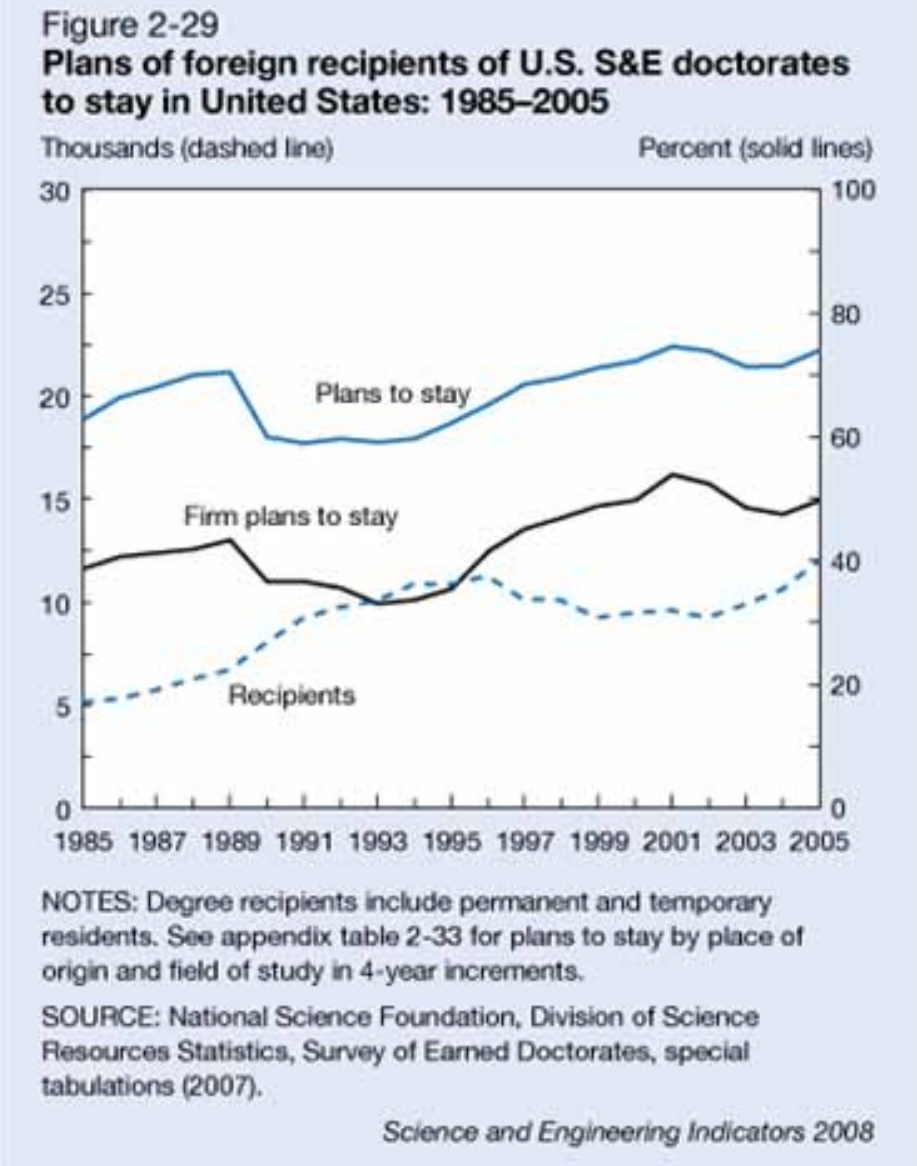

the savannahs of Sub-Saharan Africa.

A second example of a major international initiative born outside of the TE process is the successful completion of a genome project. The usefulness of the red flour beetle as a model of embryonic development has 
been established by two decades of research. Because of this, KSU faculty members led an international consortium in constructing a white paper which provided a compelling rationale for the sequencing of this genome. USDA, NIH, and other organizations agreed, and the project has just been published in Nature. An article in this issue, authored by Dr. Susan Brown, details this project.

Challenge \#3: Effectively use Graduate Education to Globalize Research

Graduate education is a global enterprise. Over a half million foreign students studied in the United States in 2005, and that our nation is not unique in hosting international students. A large number of these are graduate students and, as shown in Figure 2-39, they are studying all areas of the STEM disciplines. Often, these students come to the US grounded in a science background and rarely are they encouraged to discuss their research in their home countries. Rather, we should be using these students to cement research linkages abroad. Instead of blanket recruiting, targeted practices could select students who have shared interests with international colleagues, from the international colleague's home country, perhaps with employment opportunities with those colleagues after graduation.

International doctoral students often return to their home countries, as shown in Figure 2-26, and join the scientific workforce at home. US faculty members, therefore, have a ready source of collaborators by relying on their own graduates.
As these collaborations mature, the internationalization of graduate education could potentially be institutionalized by the establishment of joint degree programs. Within public institutions, this is difficult because of differing oversight organizations established by each state. Vibrant collaborations would be possible if these oversight boards were to grant institutions the jurisdictional authority to establish ad hoc joint degrees when strong opportunities arise.

Challenge \#4: Provide Mechanisms of Effective Financial and Administrative Oversight to Projects Overseas

There are legal and ethical challenges when faculty members initiate projects that will be managed overseas. Universities will be expected to be in compliance with the laws and regulations at home, made difficult when the funds are spent overseas. If humans are the focus of the research, for example if the project involves screening for HIV, do the processes and procedures conform to the Institutional Review Board and are the investigators aware of the laws of the host country? If the project requires special equipment that the researchers bring with them, can the researcher bring that equipment along without violating the US Export Control regulations? Does the collaborating institution have an effective grants management administration or the ability for fiscal accountability that US granting agencies expect?

KSU has a grant with the World Bank to help rebuild the College of Engineering 
within Kabul University, and we face these challenges and more.

\section{Summation}

A modern university has the obligation

to its faculty, students, and stakeholders to ensure the global nature of its research enterprise. The offices that provide the research administration for the university must have that mindset as well. At KSU, the Office of Research and Sponsored Programs strives to provide this for our stakeholders. 